\title{
Verticalización inmobiliaria y valorización de renta de suelo por infraestructura pública: un análisis econométrico del Gran Santiago, 2008-2011
}

Ernesto López-Morales. Universidad de Chile, Santiago, Chile.

Claudia Sanhueza. Universidad Mayor, Santiago, Chile.

Sebastián Espinoza. Universidad de Chile, Santiago, Chile.

Felipe Órdenes. Universidad de Chile, Santiago, Chile.

RESUMEN | Tanto las inversiones en infraestructura pública como las modificaciones a los Planes Reguladores para la construcción en altura valorizan la renta obtenible por la explotación del suelo. A partir de una base de datos relativos a departamentos nuevos vendidos entre 2008 y 2011, se realiza un cálculo para el Gran Santiago sobre el aporte porcentual de políticas del Estado a la renta de suelo, aporte realizado mediante infraestructura del sistema Metro y regulaciones urbanas. Conocidos el tamaño del departamento y precio comercial de venta, y descontados los costos de suelo y construcción, se realiza un análisis de regresión lineal múltiple con factores fijos y se obtiene que en el Gran Santiago la inversión estatal en la red de Metro incrementa un 25,6\% la ganancia de las inmobiliarias, mientras que solo lo hace en un $5,5 \%$ la de propietarios particulares de suelo. Asimismo, el factor de Coeficiente de Constructibilidad de los Planes Reguladores incrementa un 6,1\% la valorización de renta de suelo por cada punto del coeficiente, valorización que también es absorbida por las inmobiliarias. Dados estos resultados, es importante discutir la necesidad y eficiencia de tener un impuesto a la renta del suelo en el país.

PALABRAS CLAVE | mercado de suelo, mercado inmobiliario, red de metro.

ABSTRACT | Investments in public infrastructure and land upzoning aimed to high-rise redevelopment are both factors that considerably increase ground rent values in the city. Drawing on a dataset of new departments sold between 2008 and 2011, with data on unit size and commercial sale price, and discounting costs of land and construction, a multiple linear regression analysis is conducted with controlled fixed factors. The analysis shows that in Greater Santiago, state investment in Metro subway networks increases the ground rent captured by redevelopers by $25.6 \%$, whereas only $5.5 \%$ by private landowners. Likewise, each additional point of the Coefficient of Constructability (Floor Area Ratio), which are contained in the municipal-level construction codes, increases by $6.1 \%$ the value of ground rent, revenues that are also absorbed by the private redeveloper. Given these results, it is important to discuss the efficiency of having a land rent tax in the country.

KEYWORDs | land market, real estate market, metro network.

Recibido 27 de enero de 2018, aprobado el 6 de junio de 2018.

E-mails: E. López-Morales, elopez@uchilefau.cl | C. Sanhueza, claudia.sanhueza@umayor.cl | S. Espinoza, seespinoza@fen.uchile.cl |

F. Órdenes, felipe.ordenes@uchile.cl 


\section{Introducción}

En Chile, en las últimas dos décadas, el sector inmobiliario privado (desarrolladores que compran suelo y gestionan proyectos residenciales) ha reconfigurado el paisaje de los barrios centrales de las principales ciudades del país. Esto es especialmente visible en la capital, Santiago, ciudad de 7 millones de habitantes y una mancha urbana continua de 72.000 hectáreas, es decir, 720 millones de metros cuadrados de suelo.

Mayoritariamente, holdings inmobiliarios en asociación con bancos y empresas de retail han producido cientos de miles de unidades de vivienda y oficinas, agrupadas en edificios en altura. Se habla hoy de una acentuada "verticalización" de la ciudad de Santiago y otras ciudades grandes del país.

Esta renovación urbana privada se dio de la mano con una decidida demanda de "clase media", la cual se vio considerablemente subsidiada por el Estado entre 1990 y 2010 a través del Subsidio de Renovación Urbana. Mediante este instrumento, se entregaba un voucher por $200 \mathrm{UF}^{1}$ a los compradores, correspondiente al 10\% del precio máximo referencial de unidades nuevas de vivienda localizadas al interior de la ciudad (Arriagada, Moreno \& Cartier, 2007). Tal proceso ha permitido que diversos municipios "pericentrales" -es decir, aquellos ubicados en zonas interiores metropolitanas- reviertan tasas históricas de pérdida de población (Instituto Nacional de Estadísticas [INE], 2002, 2012), a la par del rápido y sostenido crecimiento de varias de estas empresas inmobiliarias ${ }^{2}$.

No obstante el apoyo estatal señalado, un problema importante en Chile es el encarecimiento generalizado del precio de la vivienda nueva que ofrece el sector privado en las zonas centrales metropolitanas. Por ejemplo, en la comuna de Santiago, municipio central de los 34 que componen el Área Metropolitana del Gran Santiago (AMGs), entre 2001 y 2015 hubo un incremento de $100 \%$ de los precios máximos de venta de vivienda nueva, tasa levemente superior a la de comunas aledańas como San Miguel, Estación Central e Independencia, que también han experimentado booms de construcción en altura en la última década (El Mercurio, 2014). A nivel general del Gran Santiago, en el ańo 2008, el promedio de metro cuadrado de departamento nuevo se acercaba a las 40 uf (Ministerio de Vivienda y Urbanismo [Minvu], 2017), pero al ańo 2015 el precio promedio metropolitano del metro cuadrado construido puesto a la venta se empinaba a 64 uf (EMOL, 2016). Esto es, un encarecimiento de casi $9 \%$ por cada ańo. A noviembre de 2017, la consultora GfK Adimark informaba un precio de departamento promedio para el Gran Santiago de 67,7 uf $/ \mathrm{m}^{2}$ (El Mercurio, 2017).

El mercado de vivienda en altura en Chile, y especialmente en Santiago, ha permitido altas rentabilidades a las empresas inmobiliarias y las sociedades de

1 Unidad de cuenta en función del IPC. Ampliamente utilizada en Chile, dado que no tiene la distorsión del efecto de la inflación en los precios. A marzo de 2019, una uf se valorizaba en 27.600 pesos chilenos, o US\$ 40 al cambio de esa fecha.

2 Por citar solo algunas de las principales: Socovesa, Paz, RVC, EuRo, etcétera. Las inmobiliarias más pequeñas cambian de nombre más seguido. Para un completo informe respecto a estas empresas, véase Wainer, Gasic y Bauzá (2016). Estas empresas, usualmente y con variaciones, controlan el proceso de compra de suelo, diseño del proyecto, gestión del financiamiento, construcción, comercialización y ventas. 
inversión que financian los proyectos, enriquecimiento generado por dos factores: primero, las inversiones del Estado en infraestructura de transporte de Metro; segundo, las modificaciones a los Planes Reguladores comunales, instrumentos que delimitan la altura, volumen y densidad permitidas en diversas zonas de la ciudad, y que entre 2008 y 2011 incrementaron tales parámetros, principalmente en toda el AMGs. Ambos factores han sido aprovechados íntegramente por las inmobiliarias, al estarles permitido explotar el suelo a su máxima intensidad posible.

A la luz de los datos aquí presentados, aparece como natural el establecimiento en Chile de un gravamen a las ganancias inmobiliarias privadas que devengan de las inversiones del Estado en la ciudad. Variantes de este gravamen son explicadas para un número alto de casos internacionales en Mirrlees et al. (2011) y Smolka (2013). En San Pablo, Brasil, Sandroni (2011) detalla la producción de instrumentos de captura de esta valorización para el financiamiento de construcciones de interés público. En un exhaustivo estudio, Blanco, Fretes y Muńoz (2016) analizan modelos de cobro de plusvalías en Argentina y Ecuador, y los casos más específicos de San Pablo, Montevideo y Bogotá. Otros estudios concuerdan en el impacto de las infraestructuras de transporte en la valorización, aunque con algunas divergencias. Para el caso de Bogotá, Colombia, Muñoz-Raskin (2010) encuentra valorización generada por el sistema de BRT Transmilenio en propiedades residenciales solo de clase media, aunque no para el resto del suelo ocupado por los estratos socioeconómicos bajos y altos. Por su parte, Bocarejo, Portilla y Pérez (2013) también detectan impacto en la valorización del suelo en esa ciudad, por causa de la existencia del BRT (sistema de Bus de Tránsito Rápido), pero solo en predios con uso comercial. En un trabajo anterior, Mendieta y Perdomo (2007), a través de una regresión de precios hedónicos, estiman un incremento de las valorizaciones de suelo también por concepto de cercanía al Transmilenio, totalizando un monto cercano al 1\% del PIB de la ciudad de Bogotá.

Problematizar la cuestión de la plusvalía de la renta de suelo por esfuerzos públicos no es algo nuevo en Chile. Ya Sabatini (2000) vinculaba la radical liberalización del suelo urbano en 1979 y las reformas de suelo posteriores, con una acentuada segregación en las ciudades del país. Sin embargo, los niveles de valorización y captura por agentes privados parecieran ser considerablemente crecientes en el país. De acuerdo con la Ley chilena, las inmobiliarias, cuando construyen y venden viviendas, prácticamente no retribuyen al Estado por las ganancias devenidas directamente por la valorización del suelo, salvo el pequeño impuesto por "permiso de construcción”, equivalente al 1,3\% del costo informado de la obra, y la Ley de Aportes al Espacio Público, promulgada en 2016, a la fecha sin aplicación, y que solo significará mitigaciones principalmente viales por un monto máximo de $44 \%$ del avalúo fiscal del terreno, muy por debajo de los montos reales de valorización de suelo observables en las últimas dos décadas en Santiago y principales ciudades de Chile. Las infraestructuras como el Metro, equipamiento público y áreas verdes, así como las modificaciones a los Planes Reguladores (cuando implican normas más flexibles y ventajosas para la construcción en altura), significan importantes factores que valorizan la renta obtenible por la explotación del suelo, actualmente en su mayoría construcción "verticalizada" (Evans, 2004). 
En el presente trabajo, se evalúan los impactos de la infraestructura pública y los cambios de normativas urbanas en la valorización de suelo apropiada por el sector privado. Para ello, se estudiaron todas las transacciones de compraventa de departamentos nuevos, ocurridas dentro de las 34 comunas que componen el AMGs, registradas por el Conservador de Bienes Raíces de Santiago (CBRS, explicado en sección "Datos"), entre los años 2008 y 2011. Se utiliza una metodología de estimación similar a la de precios hedónicos; sin embargo, la variable dependiente relevante no es el precio de la vivienda sino la renta de la tierra (denominado Renta 1 y/o Renta 2, según se explica más adelante). La regresión utiliza datos administrativos en cortes transversales repetidos en el tiempo, lo que permite controlar por efectos fijos de comuna y tiempo.

Los resultados muestran un incremento cercano al 25,6\% de las ganancias inmobiliarias (descontados todos sus costos de producción, monto denominado aquí como Renta 2) por departamentos nuevos vendidos dentro de un radio de $1 \mathrm{~km}$ a la redonda de una estación de Metro, y un incremento promedio cercano a 6,1\% de esas ganancias generado por el Coeficiente de Constructibilidad (factor contenido en el Plan Regulador Comunal o PRC, que tiene carácter de ley). Mientras tanto, los precios de venta que reciben propietarios particulares de suelo (monto denominado aquí como Renta 1) a nivel general solo se incrementan en un 5,5\% al estar ubicados dentro del radio de $1 \mathrm{~km}$ de una estación. Para la comuna de Santiago Centro solamente, el Metro genera un $48 \%$ de sobrevalorización de la ganancia inmobiliaria (Renta 2). Valorizaciones inmobiliarias muy altas ocurren también en los alrededores de la Línea 4a del Metro, principalmente en las comunas de La Cisterna, La Granja y La Florida, en el pericentro sur del AMGs. Si bien los datos corresponden a un período acotado de cuatro ańos, su carácter censal, además de tratarse de un periodo "promedio" de explotación inmobiliaria en el AMGs (ni de boom ni de decaimiento), hace de este lapso un buen representativo histórico.

Las secciones siguientes presentan un breve marco teórico referido a renta de suelo, metodología utilizada en el estudio, detalle de los resultados obtenidos, y discusión y conclusiones.

\section{Rentas de suelo capitalizada (RSC-I) y potencial (RSC-2)}

Proponer la captura pública de valor de renta de suelo no es una novedad. David Ricardo (1817, On The Principles of Political Economy and Taxation) notó que el suelo adquiere valor muchas veces por razones totalmente ajenas a su productividad, al punto de que en la literatura económica existe acuerdo sobre las bondades de un impuesto a quien capitaliza esa valorización. Más recientemente, Mirrlees et al. (2011) señalan que este impuesto es económicamente eficiente, ya que no crea distorsiones de mercado. El impuesto a la valorización de suelo es progresivo, en el sentido de que, en el contexto chileno y de la mayoría de los países, los empresarios inmobiliarios representan también a los agentes urbanos de mayores ingresos. Tal gravamen tiene por objeto retribuir al Estado la parte que le corresponde por su intervención en la valorización de suelo, y no gravar la ganancia legítima del desarrollador. Asimismo, dado que los salarios de la construcción se determinan en 
el mercado del trabajo, este impuesto no puede ser traspasado a los trabajadores. Asimismo, de existir verdadera competencia entre inmobiliarias, dicho impuesto tampoco debería traspasarse al precio de la vivienda, ya que pueden aparecer desarrolladores privados nuevos, o una agencia estatal, dispuestos a recibir una ganancia comercial normal por sus operaciones, o bien ninguna ganancia comercial en el caso del Estado, en ambos casos entregando vivienda a precio de mercado competitivo. Otro argumento de importancia es que, en ciertas condiciones, el precio final de la vivienda ya agota el excedente del consumidor y, por lo tanto, no hay traspaso del impuesto al precio. A la vez, el impuesto inmobiliario (entre otros tributos que gravan el suelo) tiende a regular los precios en la medida en que desalienta la especulación en áreas de valorización inmobiliaria promovida por obra pública. ${ }^{3}$

A nivel mundial, los estudios de brecha de renta (rent gap), es decir, el margen de ganancia económica entre valores de renta de suelo capitalizada por la sociedad y por los desarrolladores, han sido importantes para estudiar mercados inmobiliarios en zonas centrales de las ciudades en los últimos cuarenta ańos. La renta capitalizada (Renta 1) es el valor presente realmente capturado por propietarios de inmuebles existentes, y la renta potencial (Renta 2) es un valor considerablemente mayor, apropiable por el desarrollador de edificios en altura, comúnmente conocido en Chile como la "empresa inmobiliaria". Este es el único agente con capacidad técnica y financiera para explotar el suelo a esa intensidad y obtener el margen máximo de ganancia permitido por la normativa urbana, algo que no está al alcance de propietarios particulares, los que carecen de la capacidad económica y los recursos técnicos necesarios para emprender proyectos a esa escala.

Mientras que la renta capitalizada (Renta 1 ) es un valor presente internalizable por los propietarios originales, sin que existan procesos de redesarrollo inmobiliario, el segundo tipo de renta (potencial o Renta 2) solo puede ser realizado a través de la internalización de lo que los economistas neoclásicos llaman el valor de suelo "mejor y más alto" (best and highest land use; véase Marshall, 1961). Es decir, la Renta 2 solo se captura tras procesos de redesarrollo inmobiliario, sea este en rehabilitación o renovación en altura (modelo smash-and-build o "verticalizado", que actualmente predomina en la mayoría de las comunas centrales o pericentrales de Santiago). En el contexto chileno, y en algunos casos excepcionales, los propietarios de suelo que venden pueden obtener alguna participación de la Renta 2, en forma de permutas por departamentos. Sin embargo, en términos mucho más generales, es conocida la asimetría entre inmobiliarias y agentes propietarios de suelo, quienes a menudo enfrentan el riesgo de quedar atrapados aledaños a un edificio en altura (LópezMorales, Meza \& Gasic, 2014).

Existen antecedentes también para suponer que la fijación de precios de vivienda en Santiago puede responder a un modelo de "colusión tácita" (Lefort \& Vargas, 2011) o un comportamiento "líder-seguidor" (modelo de Stackelberg), donde las grandes inmobiliarias imponen los precios de oferta de vivienda y las inmobiliarias

En cualquier caso, el creciente número de compradores de vivienda para fines de inversión y/o como sustituto del cuestionado sistema de pensiones de vejez en Chile (López-Morales \& Herrera, 2018), demuestra que hay un alto excedente de consumidor en el mercado de vivienda, tema complejo de analizar pero que da para otro artículo. 
más pequeñas también aspiran a esos precios. Esta idea está respaldada por la evidencia encontrada en López Morales et al. (2014), quienes señalan que en el caso del barrio Santa Isabel, uno de los nichos principales de mercado inmobiliario en Chile durante la década del 2000, existían cuatro inmobiliarias que concentraban alrededor del $50 \%$ de la oferta de viviendas nueva. En un estudio más reciente, Wainer, Gasic y Bauzá (2016) detectaron que, de un total de 540 empresas oferentes de vivienda en el AMGs, un 50\% de la oferta se reducía a nueve empresas inmobiliarias principales, que centralizaban gran parte de su producción en las comunas de Santiago, Independencia y Estación Central, sumadas al "barrio alto" del AmGs. Por el contrario, un 60\% del total de las empresas (324) tenía tan solo un proyecto asociado. Es decir, se trata de un mercado inmobiliario concentrado en pocas empresas, especialmente si se le mira a nivel de "nichos" comunales.

Es importante observar la Renta 1, ya que es la porción de renta que le queda al antiguo propietario que vende su propiedad de suelo a las inmobiliarias y que, según López-Morales (2011, 2015) o López-Morales, Gasic y Meza (2012), cuando se trata de viviendas ocupadas, muchas veces no constituye siquiera capital mínimamente necesario para que gran parte de los vendedores del suelo puedan adquirir vivienda de reemplazo en el mismo barrio (usando el dinero que obtuvieron al vender sus casas a las inmobiliarias) o en otro barrio de condiciones de centralidad similares. Esto último genera el desplazamiento de arrendatarios o propietarios de bajos ingresos, fenómeno que se conoce como 'gentrificación'.

\section{Datos}

El objetivo principal de este artículo es estimar el valor de la Renta 2 para el caso de Santiago, y la contribución de la inversión en infraestructura pública y de los cambios normativos en ella. El análisis empírico se realiza a partir de los datos de rentas en la venta de departamentos nuevos en el Gran Santiago en el periodo 2008-2011 (se cuenta con datos administrativos de la compraventa de propiedades en ese periodo, escriturados en el CBRS). Se define como unidad de análisis cada transacción de departamento y se analiza cuánto impactan sobre dicha transacción variables relacionadas con las inversiones públicas. Para el estudio se utilizaron tres bases que permiten construir los datos de interés:

1. Conservador de Bienes Raíces de Santiago (CBRs), de carácter censal, contiene todas las transacciones de compraventa efectuadas entre los ańos 2008 y 2011 en el Gran Santiago, tanto para departamentos como para casas. En Chile, todas las compraventas de bienes raíces deben ser registradas en un CBRs, incluyendo precio pagado. Para efectos de este análisis, los resultados están referidos solo a departamentos. La base contiene datos de la fecha de transacción, precio de venta, georreferenciación del terreno (lugar y comuna de emplazamiento), superficie construida de la vivienda y superficie del terreno (solo para el caso de casas). Para el análisis de la Renta 2 se seleccionaron solo los departamentos construidos después de 2007, a fin de observar únicamente departamentos nuevos; es decir, vendidos directamente por las inmobiliarias (o, en menor probabilidad, por compradores que luego inmediatamente decidieron vender). 
2. Impuestos Internos (SII), de carácter censal, contiene información respecto a todas las propiedades existentes en Santiago por año de construcción. Se pudo hacer un cruce a través del código del sir asignado a cada manzana, y también presente en la base del cBRs. A partir de la base del sir se pudo obtener el número de edificios y número de departamentos construidos por manzana y sus superficies medidas en metros cuadrados; es decir, el total de los metros cuadrados construidos en vivienda de departamento por cada manzana del AMGs.

3. Centro de Inteligencia Territorial (сіт) de la Universidad Adolfo Ibáñez, contiene información georreferenciada asociada a la infraestructura existente en la ciudad. A partir de esta base se determina la proximidad al Metro, a servicios (educacionales, de salud) y áreas verdes, asociados a cada transacción.

La base de datos original del CBRS contiene 40.059 observaciones para el periodo comprendido entre 2008 y 2011. Al dejar solo observaciones válidas ${ }^{4}$ para las variables de interés, la base queda con 36.911 transacciones. Ese número se mantiene al unir con las bases del sir y del CiT, que vienen solo a complementar los datos de transacciones.

FIGURA I Centros educacionales, centros de salud y centros comerciales en el Área Metropolitana del Gran Santiago (AMGs)

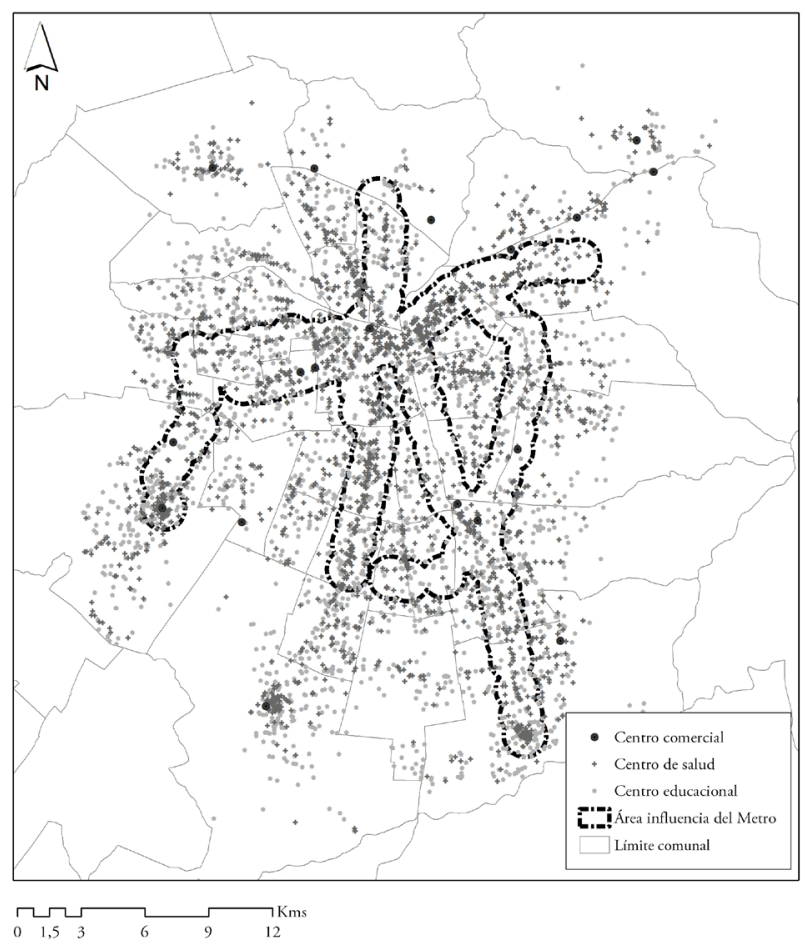

FUENTE ELABORACiÓN PROPIA CON BASE EN CATASTRO DEL CENTRO DE INTELIGENCIA TERRITORIAL (CIT), U. ADOLFO IBÁŃEZ 
Se consideraron las estaciones de Metro de Santiago en funcionamiento durante el periodo de estudio, el "área de influencia" de cada una de ellas (1 km alrededor), y el "área urbana del AMGs" en las comunas que fueron objeto de estudio. Se consideraron la distribución espacial de los centros educacionales, centros de salud y centros comerciales (figura 1), la distribución de las áreas verdes, los coeficientes de constructibilidad vigentes en los Planes Reguladores Comunales el año 2011 (figura 2), y los precios pagados por suelo entre los ańos 2008 y 2011 (figura 3).

\section{Figura 2 | Coeficientes de Constructibilidad en el Área Metropolitana del Gran} Santiago (AMGs) al ańo 2011

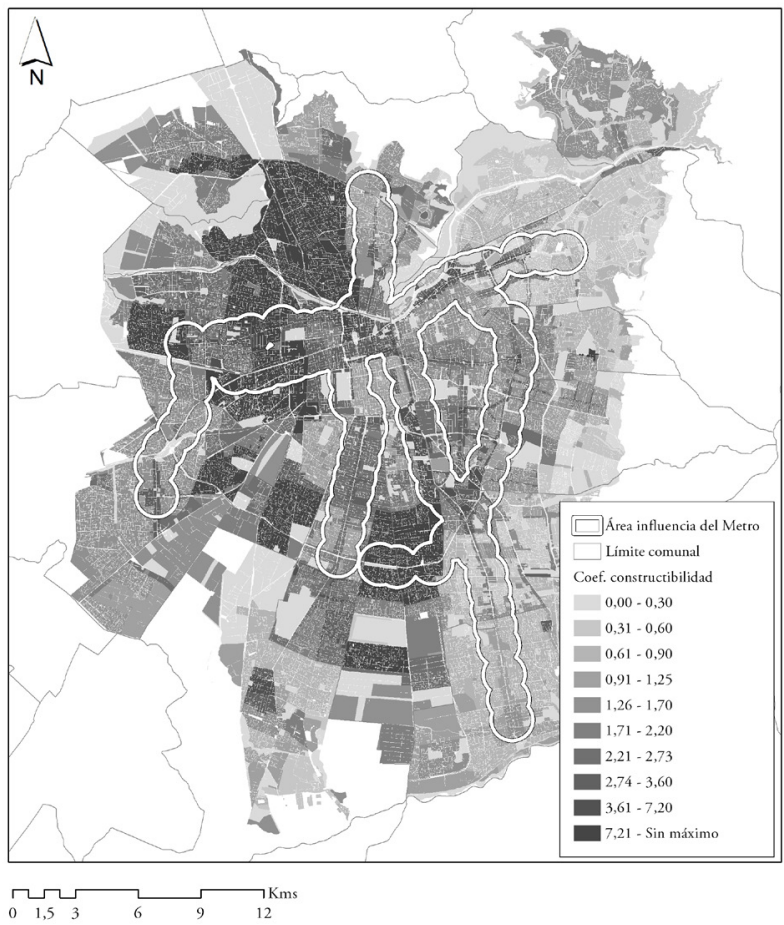

FUENTE ELABORACIÓN PROPIA CON BASE EN PLANES REGULADORES DE MUNICIPALIDADES DEL AMGS

En la tabla 1 (en anexos) se pueden observar los valores de Rentas 1 y 2 y el precio promedio de los departamentos nuevos observados -ambos medidos en $\mathrm{UF} / \mathrm{m}^{2}$ - según la distancia a alguna estación de Metro. No se aprecia una clara dependencia negativa entre distancia y renta, o distancia y precio. Podría incluso pensarse erróneamente que la relación es positiva: a más distancia, mayor es el precio. No obstante, en una alta probabilidad, esa aparente relación se debe a la existencia de otras variables no consideradas, como, por ejemplo, la composición socioeconómica del entorno. Si en las zonas donde se construyen más departamentos las viviendas de la gente con más dinero, que a su vez serán las viviendas más caras, se encuentran alejadas de 
los centros y subcentros y no existen estaciones de Metro que las conecten, inevitablemente los precios promedio de los departamentos más alejados del Metro serán más altos por esta vía. La tabla también muestra la distribución de datos entre las distintas distancias.

FIGURA 3 | Precio de suelo pagado por propiedades "no departamentos" usado para estimar Renta 1

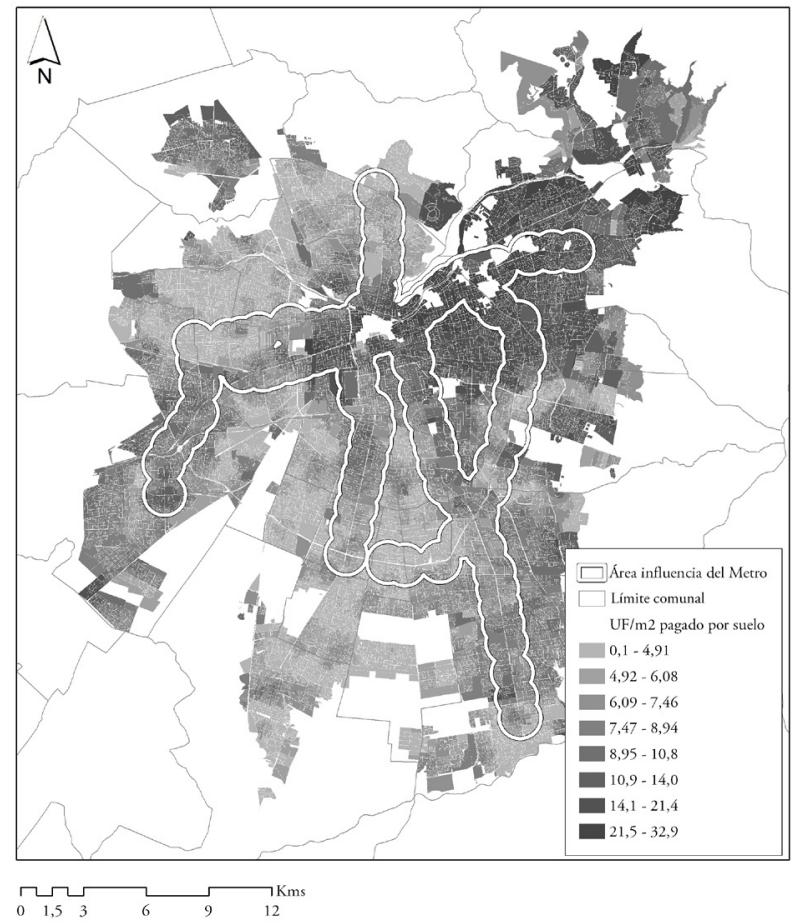

FUENTE ELABORACIÓN PROPIA CON BASE EN CONSERVADOR DE BIENES RAÍCES DE SANTIAGO

TABla I | Precio promedio según distancia al Metro

\begin{tabular}{|c|c|c|c|c|}
\hline $\begin{array}{l}\text { DISTANCIA AL } \\
\text { METRO }\end{array}$ & $\begin{array}{c}\text { CANTIDAD DE } \\
\text { DEPARTAMENTOS }\end{array}$ & $\begin{array}{c}\text { MEDIA PRECIO } \\
\text { DEPARTAMENTOS } \\
\left(\mathrm{UF} / \mathrm{M}^{2}\right)\end{array}$ & $\begin{array}{c}\text { MEDIA RENTA I } \\
\left(\mathbf{U F} / \mathbf{M}^{2}\right)\end{array}$ & $\begin{array}{c}\text { MEDIA RENTA } 2 \\
\left(\mathbf{U F} / \mathbf{M}^{2}\right)\end{array}$ \\
\hline Entre 0 y $500 \mathrm{~m}$ & 14.100 & 37,4 & 13,3 & 16,1 \\
\hline Entre 500 y $1.000 \mathrm{~m}$ & 8.869 & 35,8 & 10,5 & 15,3 \\
\hline $\begin{array}{l}\text { Entre } 1.000 \text { y } 2.000 \\
\mathrm{~m}\end{array}$ & 8.965 & 36,2 & 10,8 & 13,6 \\
\hline $\begin{array}{l}\text { Entre } 2.000 \text { y } 3.000 \\
\mathrm{~m}\end{array}$ & 3.225 & 41,1 & 13,2 & 17 \\
\hline Más de $3.000 \mathrm{~m}$ & 1.752 & 45,4 & 8,1 & 22,9 \\
\hline
\end{tabular}

FUENTE ELABORACIÓN PROPIA. SE INCLUYEN TODOS LOS DEPARTAMENTOS CONSIDERADOS EN LA MUESTRA. LOS RANGOS DE DISTANCIA SON INCLUSIVE EL LÍMITE INFERIOR Y NO INCLUSIVE EL SUPERIOR. POR EJEMPLO, PARA EL RANGO ENTRE $50 O \mathrm{Y}$ I.OOO SE CONSIDERAN LOS DEPARTAMENTOS QUE ESTÁN A 500 METROS O MÁS HASTA LOS QUE ESTÁN A MENOS DE I.OOO METROS 
En la tabla 2 se muestra el promedio y la desviación estándar de las distintas variables que se utilizaron posteriormente en el análisis empírico. Puede notarse que el promedio del valor de Renta 2 por cada metro cuadrado de departamento en el Gran Santiago es de 15,7 uf $/ \mathrm{m}^{2}$, mientras que el valor de la Renta 1 (precio que se estima pagado por inmobiliarias a propietarios de suelo) es de $11,7 \mathrm{uF} / \mathrm{m}^{2}$, y el precio promedio de departamentos nuevos observados es de $37,4 \mathrm{uF} / \mathrm{m}^{2}$. Por otro lado, el Coeficiente de Constructibilidad en promedio es de 3,7, aunque con importantes variaciones. En tanto, la distancia al Metro de los departamentos observados es en promedio de $1,07 \mathrm{~km}$, concentrando aproximadamente un $62 \%$ de las observaciones dentro del radio de $1 \mathrm{~km}$. Por otro lado, la distancia a servicios varía según el que se considere; en promedio, los departamentos están a 265 y 252 metros de distancia de centros de salud y centros educacionales, respectivamente, y a $2,3 \mathrm{~km}$ de malls o centros comerciales.

TABLA 2 Estadística descriptiva variables de interés

\begin{tabular}{|l|c|c|}
\hline \multicolumn{1}{|c|}{ VARIABLE } & MEDIA & DESVIACIÓN ESTÁNDAR \\
\hline Renta capitalizada $1\left(\mathrm{UF} / \mathrm{m}^{2}\right)$ & 11,7 & 6,7 \\
\hline Renta capitalizada $2\left(\mathrm{UF} / \mathrm{m}^{2}\right)$ & 15,7 & 8,7 \\
\hline Precio $\left(\mathrm{UF} / \mathrm{m}^{2}\right)$ & 37,4 & 10,6 \\
\hline Coeficiente de constructibilidad & 3,7 & 2,9 \\
\hline Radio influencia Metro $(1 \mathrm{~km})$ & $62 \%$ & 11,8 \\
\hline Distancia a metro & 10,7 & 1,8 \\
\hline Distancia a centro educacional & 2,5 & 2,5 \\
\hline Distancia a centro de salud & 2,7 & 13,7 \\
\hline Distancia a mall & 23,5 & 693.880 \\
\hline Área verde en $500 \mathrm{~m}$ & 164.016 & $\mathrm{~m}$ \\
\hline
\end{tabular}

FUENTE ELABORACIÓN PROPIA. SE INCLUYEN TODOS LOS DEPARTAMENTOS CONSIDERADOS EN LA MUESTRA. PARA RADIO DE INFLUENCIA METRO SE CALCULA EL PORCENTAJE DE DEPARTAMENTOS QUE SE ENCUENTRAN EN UN RADIO DE I.OOO METROS. LAS DISTANCIAS SE MIDEN EN CIENTOS DE METROS

Finalmente, la tabla 3 muestra algunas de las variables de interés y su evolución en el periodo 2008-2011. Puede notarse que, en términos generales, las variables estudiadas se mantienen relativamente constantes en el periodo, presentando leves aumentos. Tanto el precio de los departamentos nuevos como la Renta 2 y Renta 1 muestran un leve ascenso, coherente con los aumentos de precio generales en la economía. Por otra parte, el Coeficiente de Constructibilidad promedio disminuye ligeramente. El porcentaje de departamentos que están en el radio de $1 \mathrm{~km}$ respecto de una estación de Metro es el que más cambia, con un alza aproximada de $10 \%$. Este aumento notable se debe principalmente a la habilitación de nuevas líneas en el periodo y la posible mayor oferta al interior de esa zona. Finalmente, puede notarse que la compraventa de departamentos estuvo entre 7.433 (en 2008) y 10.142 (en 2009) unidades. 
TABLA 3 | Variables de interés por año

\begin{tabular}{|l|c|c|c|c|}
\hline \multicolumn{1}{|c|}{ VARIABLE } & $\mathbf{2 0 0 8}$ & $\mathbf{2 0 0 9}$ & $\mathbf{2 0 I 0}$ & 20I I \\
\hline Renta capitalizada $1\left(\mathrm{UF} / \mathrm{m}^{2}\right)$ & 11,7 & 12,4 & 11,4 & 11,4 \\
\hline Renta capitalizada $2\left(\mathrm{UF} / \mathrm{m}^{2}\right)$ & 15,2 & 15,3 & 15,7 & 16,5 \\
\hline Precio $\left(\mathrm{UF} / \mathrm{m}^{2}\right)$ & 36,5 & 37,4 & 37 & 38,3 \\
\hline Coeficiente de constructibilidad & 3,8 & 3,8 & 3,7 & 3,6 \\
\hline Radio influencia Metro $(1 \mathrm{~km})$ & $59 \%$ & $59 \%$ & $63 \%$ & $68 \%$ \\
\hline Frecuencia & 7.433 & 10.142 & 9.232 & 10.104 \\
\hline
\end{tabular}

FUENTE ELABORACIÓN PROPIA. SE INCLUYEN TODOS LOS DEPARTAMENTOS CONSIDERADOS EN LA MUESTRA. PARA RADIO DE INFLUENCIA METRO SE CALCULA EL PORCENTAJE DE DEPARTAMENTOS QUE SE ENCUENTRAN EN UN RADIO DE I.OOO METROS

\section{Metodología}

El estudio utiliza el modelo de regresión para analizar el impacto sobre la Renta 1 y 2 de dos políticas públicas: la inversión en líneas de Metro y la definición de regulaciones municipales de la edificación. La Renta 1 se entiende como los precios de venta de predios ocupados por casas, bodegas y sitios eriazos, observables en la Base del CBRs, durante el periodo de la muestra. La Renta 2 fue más compleja de obtener. La ecuación 1 muestra que la Renta 2 del departamento $i$ en la comuna $c$ en el año $t\left(r_{i c}\right)$ se obtiene restando al precio de venta $\left(P_{i c t}\right)$, el costo del suelo $\left(C S_{i c}\right)$ y el costo de contrucción $\left(C C_{i c t}\right)$ asociados al departamento $i$ en la comuna $c$ en el tiempo $t$.

$$
r_{i c t}=P_{i c t}-C S_{i c t}-C C_{i c t}
$$

El precio de venta del departamento $\left(P_{i c t}\right)$ es directamente observado en los datos de CBRs. El costo del suelo $\left(C S_{i c}\right)$ asociado al departamento no es observable directamente, ya que no es posible determinar cuánto le costó el predio a la inmobiliaria previo a construir el edificio en altura, por lo que se estimó a partir del promedio de los datos de precio de compra de casas, bodegas y sitios eriazos 500 metros a la redonda del centroide de la manzana (dato contenido en CBRS). Conocido el total de metros cuadrados de construcción nueva de departamentos en una manzana (dato SII), solo se requería estimar el total de metros cuadrados de suelo ocupado por dichos edificios. Ese tamaño se estimó al dividir el total de metros cuadrados construidos por el Coeficiente de Constructibilidad establecido para esa manzana (se supone que las inmobiliarias construyen al máximo permitido por dicho coeficiente). Una vez conocido el total de metros cuadrados de suelo, se pudo imputar el costo de suelo proporcional a cada metro cuadrado nuevo construido (considerando $10 \%$ de áreas comunes, que también se reparten entre cada metro cuadrado construido de departamento nuevo).

Finalmente, el costo directo de construcción $\left(C C_{i c}\right)$ se asume en promedio idéntico e igual a $16 \mathrm{uf} / \mathrm{m}^{2}$ para para todas las construcciones en Santiago, lo cual está dentro de un espectro aceptado por el mundo inmobiliario en Chile para edificación en altura (costo directo de materiales más mano de obra; se excluyen costos indirectos de venta y marketing), y se trata de un valor cuya variación en cualquier caso no afecta el resultado. Un análisis de sensibilidad de los parámetros máximos 
de costos de construcción (variaciones en rango de 12 a $20 \mathrm{uF} / \mathrm{m}^{2}$ ) y coeficientes de constructibilidad (variaciones en rango de 6 a 14) mostró que si bien existen diferencias de resultados dependiendo de si son supuestos bajos o altos, se trata de variaciones bastante marginales y que van en línea de los resultados antes mencionados (tabla excluida por razones de espacio).

Para evaluar la influencia de las estaciones de Metro sobre la Renta 2, se determinó un radio de influencia de $\mathrm{m}$ metros a la redonda de la estación, donde $\mathrm{M}$ es diferentes radios de área de influencia (250, 500 y 1000 metros o $1 \mathrm{~km})$, para así evaluar a partir de los datos la distancia a la que se da una mayor valoración. Se encuentra, a partir de dichas estimaciones, ${ }^{5}$ que la distancia al Metro en torno a la que existe una mayor valoración es precisamente la de $1 \mathrm{~km}$. Para corroborar dicho análisis se graficó el promedio de precios y rentas para cada distancia al Metro, encontrándose claramente que la valoración existe, en promedio, hasta la distancia de $1 \mathrm{~km}$. Asimismo, se definió si el departamento se encontraba dentro del área de influencia por línea del Metro, de tal forma de estudiar si existe una valorización heterogénea por línea. Por otro lado, para estudiar las regulaciones a la edificación se utilizan los coeficientes de constructibilidad válidos para la manzana en la que están edificados los departamentos. Los coeficientes de constructibilidad permiten determinar cuánto es lo máximo que se puede construir en un predio determinado. Entre más altos son los departamentos, más se puede construir en el predio. En la muestra utilizada en este estudio, el coeficiente normado se mueve entre 0 y 7,2. Si el coeficiente no estaba definido en el Plan Regulador Comunal correspondiente, se imputó un valor de 10, mayor al máximo real, para que así reflejase la absoluta desregulación existente (este valor de coeficiente actualmente se encuentra en edificios nuevos, ubicados en comunas como Estación Central o Santiago Centro; véase López-Morales et al., 2012, 2014).

Para obtener una correcta apreciación de los coeficientes de la estimación, se utilizan controles relacionados con las características del departamento y su entorno, entre los que se cuentan: distancia a establecimientos educacionales, a establecimientos de salud, ${ }^{6}$ a centros comerciales (subcentros) y cantidad de áreas verdes disponibles en 500 metros a la redonda. Implícitamente se cree que estas variables podrían determinar, por la vía de afectar el precio, la Renta 2 obtenida, y al estar correlacionadas con las variables de interés -tanto estar en el radio de influencia de estaciones de Metro como las regulaciones de coeficientes de constructibilidad-, podrían sesgar las estimaciones obtenidas. Adicionalmente, se agregan al modelo efectos fijos tanto por comuna como por año de construcción y año de venta. Los efectos fijos por comuna permiten controlar por características existentes en las comunas que se mantienen fijas en el tiempo y que permanecen no observables, como, por ejemplo, el acceso a puestos de trabajo o determinadas características sociales $-\mathrm{o}$ su preferencia-. Los efectos fijos por tiempo permiten controlar por

5 Resultados se encuentran disponibles bajo solicitud a los autores.

6 Una limitación de este estudio es que no se contó con tamaño, nivel de complejidad o calidad de los establecimientos de salud y educación para el análisis. Ello puede arrojar ciertos sesgos, dado que no representa lo mismo la cercanía con un hospital que con un centro básico de atención de salud. 
tendencias temporales que se mantienen fijas para toda la muestra para los distintos años, como, por ejemplo, crisis o auges económicos o algún shock tecnológico que afectó a toda la industria por igual.

La especificación del modelo econométrico se encuentra en la ecuación 2, donde $r_{i c t}$ es el logaritmo natural ${ }^{7}$ de la Renta 2 obtenida a partir de la transacción del departamento $i$ en la comuna $c$ en el tiempo $t ; D M_{i c t}$ una dummy que toma el valor 1 si dicho departamento se encuentra en el radio de influencia del Metro; $P P_{i c t}$ una variable que toma el valor del Coeficiente de Constructibilidad vigente en la manzana del departamento $i$ en la comuna $c$ en el año $t ; X_{i c t}$ un vector que contiene las variables de control antes mencionadas, $F_{c}$ y $F_{t}$ son los efectos fijos de comuna y tiempo.

$$
r_{i c t}=\alpha_{0}+\beta * D M_{i c t}+\theta * P P_{i c t}+\delta X_{i c t}+F_{c}+F_{t}+\varepsilon_{i c t}
$$

Hay que notar que la muestra de los datos podría estar sesgada, ya que solamente estamos observando aquellas unidades ofrecidas que fueron vendidas, no las que aún no han sido vendidas. Esto podría ser un problema si las unidades que no han sido vendidas (no observadas) se encuentran correlacionadas con la distancia al Metro. Efectivamente, es más probable que las unidades no vendidas estén más lejos del Metro, en cuyo caso estaremos subestimando el efecto de la distancia al Metro en la renta. Para verificar esto, observamos que el promedio de velocidad de venta del stock completo de departamentos construidos en ese período es 20 meses (Cámara Chilena de la Construcción, 2011a, 2011b); siendo así, los departamentos construidos en el año 2008 deberían estar vendidos en el período 2008-2011. Por lo tanto, estimamos la misma especificación (1) solamente para departamentos nuevos construidos el ańo 2008 y contrastamos los resultados con los de la muestra total de departamentos vendidos en dicho período, a fin de evaluar este sesgo de selección.

Las ventajas de los datos y la metodología aquí presentados es que recogen la totalidad de las transacciones en el AMGs, dado que el dato del CBRS tiene carácter censal. Asimismo, se recoge el valor de la ganancia inmobiliaria posconstrucción, descontados todos los costos de producción de los edificios y no solo el precio pagado por propiedades, como hace Trivelli (varios ańos), o simplemente la variación de precio de viviendas (agregando atributos "internos" de la vivienda) que realizan, por ejemplo, Agostini y Palmucci (2008).

\section{Resultados}

En la tabla 4 se presentan los resultados para las estimaciones de la ecuación (1) descrita en la sección anterior. En términos generales, la columna 3 es la mejor estimación disponible, ya que incluye todos los controles. La columna 1 presenta los resultados sin considerar efectos fijos ni por tiempo ni por comuna. La columna 2 presenta la estimación considerando solo efectos fijos por tiempo. Finalmente, la columna 3 presenta la mejor estimación que utiliza efectos fijos por tiempo y comuna y permite controlar por los problemas antes mencionados.

7 El logaritmo natural permite interpretar los coeficientes como semielasticidades (variación porcentual de la Renta 2 ante cambios de nivel en las variables explicativas). 
TABLA 4 Estimaciones de Renta 2 para el Gran Santiago

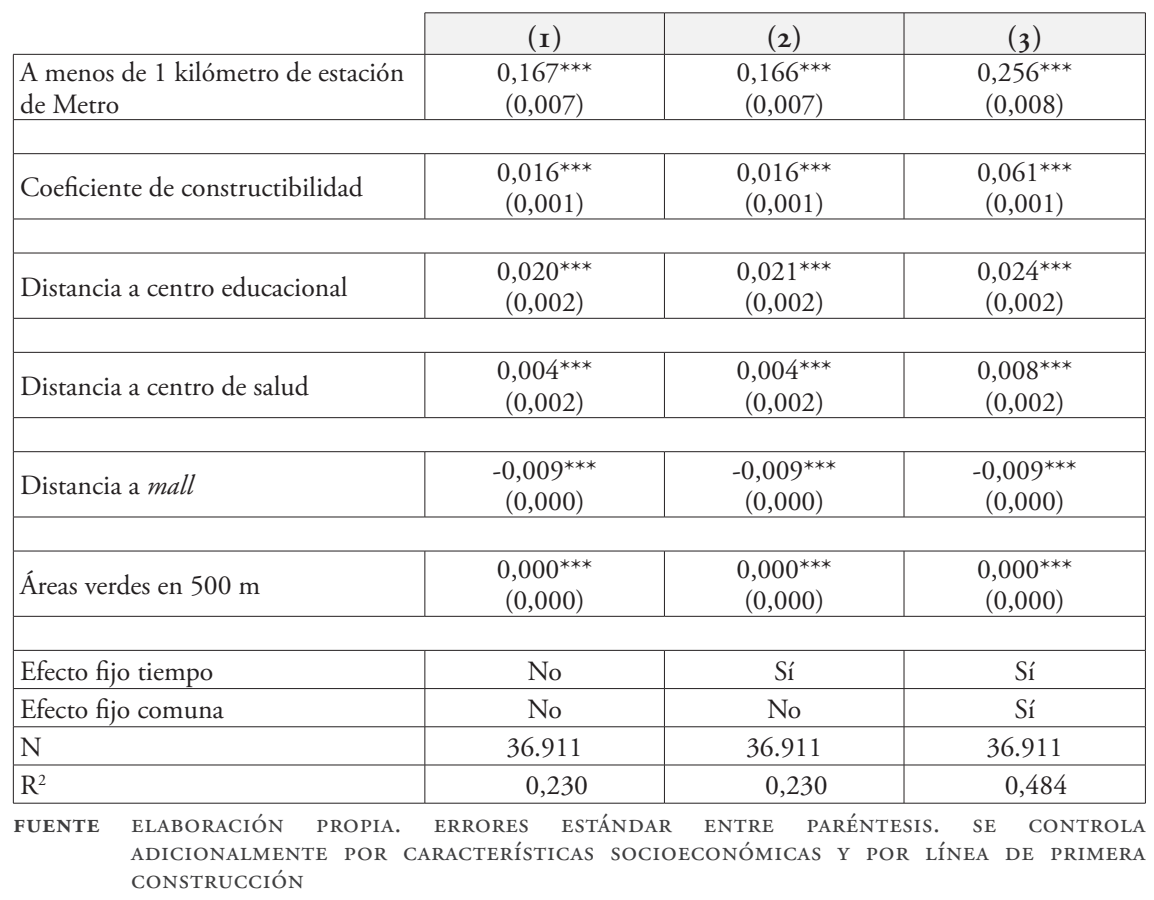

Según la especificación mostrada en la columna 1, estar en el radio de influencia de alguna estación de Metro aumenta en promedio un 16,7\% la Renta 2 percibida por el inmobiliario. Por otra parte, se encuentra que un aumento en una unidad del Coeficiente de Constructibilidad aumenta en un 1,6\% la Renta 2 capitalizada por la inmobiliaria. En el límite, si el Coeficiente de Constructibilidad pasara de la mínima regulación 1 a la regulación máxima 10, el aumento en la renta que obtendrían los inmobiliarios sería de aproximadamente 16\%. Los dos efectos se mantienen relativamente constantes en la especificación mostrada en la columna $2 .{ }^{8}$ No obstante, el no considerar las características fijas comunales trae como consecuencia un coeficiente sesgado.

$\mathrm{Al}$ analizar la columna 3, que contiene la mejor especificación disponible, se constata que el estar en el radio de influencia del Metro aumenta en promedio en un $25,6 \%$ la Renta 2 . Se constata también en esa misma especificación que el alejarse de centros educacionales y de salud tendería a aumentar la Renta 2 obtenida (un $2,4 \%$ y un $0,8 \%$, respectivamente). Lo anterior puede darse por un efecto saturación a raíz del ruido y las externalidades negativas asociadas a estar cerca de estos lugares. En esa línea, es interesante también que la cercanía a malls y centros comerciales tiene un efecto positivo -aunque relativamente pequeño- sobre la Renta 2 que se puede obtener. Dicho efecto promedio es cercano al 0,9\%. Finalmente, la

8 Tiene sentido, ya que los datos muestran que no existen grandes variaciones en términos de Renta 2 entre ańos. 
disponibilidad de áreas verdes en 500 metros a la redonda tiene un efecto estadísticamente significativo, pero cercano a 0 .

Como se discute en la metodología, se estimó el mismo modelo condicional a que los departamentos fueron construidos el año 2008 para evaluar el posible sesgo de selección (tabla excluida por razones de espacio). Los resultados muestran que la Renta 2 aumenta en promedio alrededor de un 27,3\% cuando el departamento se encuentra ubicado a menos de $1 \mathrm{~km}$ de alguna estación de Metro. Esto muestra que efectivamente hay un sesgo de selección de la muestra por las unidades no vendidas, y las estimaciones que estamos presentando son una cota inferior del verdadero efecto de la infraestructura en la Renta 2.

Adicionalmente, se estimó el mismo modelo, pero solo para las comunas de Santiago, Providencia y Las Condes, visible en la tabla 5. Se consideran efectos fijos de tiempo y controles. Se eligieron dichas comunas porque, por un lado, son las que tienen el mayor número de observaciones; y por el otro, muestran heterogeneidades interesantes, como se aprecia a continuación.

TABLA 5 Estimaciones de Renta 2 por comunas

\begin{tabular}{|c|c|c|c|}
\hline & $\begin{array}{c}\text { (I) } \\
\text { SANTIAGO }\end{array}$ & $\begin{array}{c}\text { (2) } \\
\text { PROVIDENCIA }\end{array}$ & $\begin{array}{c}\text { (3) } \\
\text { LAS CONDES }\end{array}$ \\
\hline $\begin{array}{l}\text { A menos de } 1 \mathrm{~km} \text { de estación de } \\
\text { Metro }\end{array}$ & $\begin{array}{c}0,457^{* * *} \\
(0,014)\end{array}$ & $\begin{array}{l}0,197^{* * *} \\
(0,032)\end{array}$ & $\begin{array}{l}0,527^{* * *} \\
(0,021)\end{array}$ \\
\hline Regulación & $\begin{array}{c}0,057^{* * *} \\
(0,008)\end{array}$ & $\begin{array}{l}0,084^{* * *} \\
(0,015)\end{array}$ & $\begin{array}{c}0,016 \\
(0,002) \\
\end{array}$ \\
\hline Distancia a centro educacional & $\begin{array}{l}-0,017^{* * *} \\
(0,006)\end{array}$ & $\begin{array}{l}-0,023^{* * *} \\
(0,007)\end{array}$ & $\begin{array}{l}-0,012 \\
(0,004)\end{array}$ \\
\hline Distancia a centro de salud & $\begin{array}{c}0,044^{* * *} \\
(0,005)\end{array}$ & $\begin{array}{l}0,026^{* * *} \\
(0,007)\end{array}$ & $\begin{array}{c}-0,017^{* *} \\
(0,005) \\
\end{array}$ \\
\hline Distancia a mall & $\begin{array}{c}-0,019^{* * *} \\
(0,001)\end{array}$ & $\begin{array}{l}-0,024^{* * *} \\
(0,002)\end{array}$ & $\begin{array}{l}0,014^{* * *} \\
(0,001)\end{array}$ \\
\hline Área verde en $500 \mathrm{~m}$ & $\begin{array}{c}0,000 \\
(0,000)\end{array}$ & $\begin{array}{c}0,000 \\
(0,002)\end{array}$ & $\begin{array}{l}-0,015^{* * *} \\
(0,000)\end{array}$ \\
\hline Efecto fijo tiempo & Sí & Sí & Sí \\
\hline Efecto fijo comuna & No aplica & No aplica & No aplica \\
\hline $\mathrm{N}$ & 11.239 & 4.659 & 2.365 \\
\hline $\mathrm{R}^{2}$ & 0,350 & 0,322 & 0,336 \\
\hline $\begin{array}{ll}\text { FUENTE } & \text { ELABORACIÓN PROPIA. } \\
& \text { ADICIONALMENTE POR } \\
& \text { CONSTRUCCIÓN }\end{array}$ & $\begin{array}{l}\text { ERRORES ESTÁNDAR } \\
\text { RACTERÍSTICAS SOCIO }\end{array}$ & $\begin{array}{l}\text { ENTRE PARÉNTE } \\
\text { ECONÓMICAS Y POF }\end{array}$ & $\begin{array}{l}\text { RIS. SE CONTROLA } \\
\text { R LÍNEA DE PRIMERA }\end{array}$ \\
\hline
\end{tabular}

En la comuna de Santiago se encuentra que la Renta 2 aumenta en promedio alrededor de un 45,7\% dentro del radio de $1 \mathrm{~km}$ de una estación de Metro, respecto de 
aquellos que se encuentran a mayor distancia. Se observa también que, al interior de la comuna, un aumento en una unidad del Coeficiente de Constructibilidad permite aumentar en un 5,7\% la Renta 2 percibida. En relación con las otras variables, 100 metros más lejos de un mall reducen en un 1,9\% la Renta 2. La distancia a centros de salud, en tanto, tiene un efecto significativo de $4,4 \%$ en la Renta 2 por cada 100 metros de lejanía en el caso de los de salud, mientras que la distancia a centros educacionales tiene un efecto significativo de $-1,9 \%$ en el caso de 100 metros más de lejanía; esto es, la gente valora vivir cerca de los establecimientos educacionales, a diferencia de lo que pasa con los datos a nivel del Gran Santiago. Finalmente, las áreas verdes en un radio de 500 metros tienen un efecto que no es estadísticamente significativo.

En la comuna de Providencia, en tanto, el estar situado en un radio de un kilómetro del Metro aumenta en un 19,7\% la Renta 2, valor inferior al promedio metropolitano, en una comuna donde el acceso a distintas modalidades de transporte público y privado está más uniformemente repartido. Asimismo, en esta comuna, una unidad adicional de Coeficiente de Constructibilidad aumenta en un $8,4 \%$ la Renta 2 que perciben las inmobiliarias, valor considerablemente mayor al resto de las comunas. Ambas disparidades se explican por las regulaciones más estrictas que existen en esta comuna, que hacen aquí de cualquier incremento de constructibilidad un factor altamente apreciado en el mercado inmobiliario. El resto de variables se comporta de manera similar que en la comuna de Santiago y en el Gran Santiago (efecto negativo de los centros educacionales, es decir, la gente valora que estén cerca y en la medida que se alejen, baja la Renta 2; y efecto positivo de los centros de salud, es decir, la gente valora estar lejos de ellos, y a medida que estén más lejos, aumenta la Renta 2).

El tercer caso, la comuna de Las Condes, presenta una mayor capitalización por cercanía al Metro. En dicha comuna se encuentra que la Renta 2 aumenta en alrededor de un 52,7\% al estar en el radio de $1 \mathrm{~km}$ del Metro. Sin embargo, aquí los cambios en Coeficiente de Constructibilidad pareciesen no tener un efecto estadísticamente significativo, al contrario de las otras dos comunas analizadas. El coeficiente asociado a la distancia a centros educacionales no es estadísticamente significativo, mientras que la distancia a centros comerciales muestra que cada 100 metros más alejados de malls, la renta aumenta en un 1,4\% (se obtiene una mayor rentabilidad entre más lejos se está de aquellos centros). Por último, por cada 100 metros de distancia a centros de salud se reduce la renta en un $1,7 \%$, siendo el único de los casos analizados donde ello sucede. Una posible hipótesis es que exista una mayor valoración de los centros de salud privados apostados en esa zona de la ciudad (la tercera de ingresos más altos en el Gran Santiago).

Se revisaron también posibles heterogeneidades en la capitalización por cercanía al Metro para distintas líneas de la red metropolitana. La tabla 6 muestra las regresiones, incluyendo desagregadamente efectos en la Renta 2 por cercanía a cada línea de Metro. En términos generales, esta estimación debería permitirnos aislar el efecto de cada línea por separado. En el límite, la especificación anterior no permite encontrar la capitalización exacta para aquellas líneas que están demasiado cerca, ya que no es capaz de diferenciar para un departamento ubicado en la mitad entre dos 
estaciones de distintas líneas si su capitalización es por la Línea A o la Línea B. Esto podría ser un problema relevante para este estudio al estudiar la Línea 1 y Línea 5, que en un tramo importante de la comuna de Santiago, desde Estación Plaza Italia hasta Estación Gruta de Lourdes, transcurren de forma paralela.

TABla 6 | Estimaciones de Renta 2 por líneas de Metro

\begin{tabular}{|c|c|c|c|}
\hline & (I) & (2) & (3) \\
\hline Línea 1 & $\begin{array}{l}0,223^{* * *} \\
(0,009)\end{array}$ & $\begin{array}{l}0,231^{* * *} \\
(0,009)\end{array}$ & $\begin{array}{l}0,178^{* * *} \\
(0,009)\end{array}$ \\
\hline Línea 2 & $\begin{array}{l}-0,063^{* * *} \\
(0,008)\end{array}$ & $\begin{array}{l}-0,065^{* * *} \\
(0,008)\end{array}$ & $\begin{array}{l}0,173^{* * *} \\
(0,011)\end{array}$ \\
\hline Línea 4 & $\begin{array}{l}0,454^{* * *} \\
(0,013)\end{array}$ & $\begin{array}{c}0,457^{* * *} \\
(0,013) \\
\end{array}$ & $\begin{array}{l}0,160^{* * *} \\
(0,012)\end{array}$ \\
\hline Línea 4a & $\begin{array}{l}-0,229^{* * *} \\
(0,025)\end{array}$ & $\begin{array}{l}-0,233^{* * *} \\
(0,025)\end{array}$ & $\begin{array}{l}0,222^{* * *} \\
(0,027)\end{array}$ \\
\hline Línea 5 & $\begin{array}{l}-0,022^{* * *} \\
(0,008)\end{array}$ & $\begin{array}{l}-0,026^{* * *} \\
(0,008)\end{array}$ & $\begin{array}{l}0,111^{* * *} \\
(0,008)\end{array}$ \\
\hline Regulación & $\begin{array}{l}0,022^{* * *} \\
(0,001)\end{array}$ & $\begin{array}{c}0,022^{* * *} \\
(0,001)\end{array}$ & $\begin{array}{l}-0,055^{* * *} \\
(0,001)\end{array}$ \\
\hline Efecto fijo tiempo & No & Sí & Sí \\
\hline Efecto fijo comuna & No & No & Sí \\
\hline $\mathrm{N}$ & 36.911 & 36.911 & 36.911 \\
\hline $\mathrm{R}^{2}$ & 0,259 & 0,261 & 0,483 \\
\hline
\end{tabular}

$\mathrm{Al}$ realizar las estimaciones, se encuentra que la cercanía a alguna estación de Metro de la Línea 1 (la más antigua, que comenzó a operar en 1975, pero cuya última extensión al "barrio alto" fue inaugurada recién en 2009) permite aumentar la Renta 2 en un 17,8\%. Por su parte, en la Línea 2 (inaugurada en 1978), el aumento es de un 17,3\%. La Línea 4 (inaugurada en 2005), en tanto, permite aumentar la Renta 2 en un 16\% y la Línea 4a (ramal de la Línea 4 inaugurado en 2006), en un 22,2\%. La Línea 5, por último (inaugurada en 1997), es la que pareciese tener un menor aumento en la Renta 2, que alcanzaría un 11,1\%. En conclusión, el desarrollo inmobiliario gatillado alrededor de numerosas estaciones de las líneas de Metro 2 y 4, especialmente en la parte sur de la metrópolis de Santiago, se ha beneficiado durante el periodo 2008-2011 de inversiones públicas en porcentajes notablemente mayores que el resto de las líneas.

La altísima valorización a lo largo de la Línea 2 es interesante, porque esta línea cruza dos de los nichos de mayor intensidad inmobiliaria del AMGs: las comunas de San Miguel y La Cisterna. El ramal 4b, que conecta la comuna de La Cisterna con las comunas de Puente Alto (con una tendencia creciente al incremento de 
precios de suelo de más de $1.000 \%$ entre 1990 y 2010: véase Trivelli, 2011; y la más populosa de Chile, con 586.000 residentes: véase INE, 2012) y Nuñoa, comuna de "clase media" del oriente de Santiago, todas ellas con activa producción inmobiliaria residencial en altura en los últimos veinte años.

Se realizó una última estimación con el fin de comprobar cuánto de la Renta 1 (la ganancia que captura un propietario de suelo al vender su propiedad, usualmente construcciones de casas o edificios de baja altura) está generado por el Metro y regulación de suelo (se excluye tabla por razones de espacio). Este análisis permitió corroborar la veracidad del supuesto según el cual los propietarios de suelo se benefician de las inversiones públicas en el sistema Metro. Los resultados sorprenden por lo bajos, con solo un 5,5\% de valorización del precio de casas vendidas dentro del radio de 1.000 metros a una estación de Metro, respecto a aquellas que se vendieron fuera del radio. Si se compara con los incrementos en la ganancia de las inmobiliarias, de más de un 25\%, queda claro que son estas últimas las que se benefician principalmente de las inversiones públicas de Metro, y no los propietarios de suelo. En esa línea, se puede observar que los cambios de regulación (Coeficiente de Constructibilidad) no tienen efectos sobre la Renta 1, mostrando también que son principalmente las inmobiliarias las que se benefician cuando existen aumentos de constructibilidad en los Planes Reguladores Comunales.

\section{Conclusiones}

Los resultados muestran que, efectivamente, a nivel del Área Metropolitana del Gran Santiago (AMGS), la cercanía al Metro aumenta la Renta 2 (ganancia neta de las inmobiliarias) en aproximadamente $25,6 \%$, y que los cambios regulatorios implican, por cada punto de Coeficiente de Constructibilidad, un aumento de cerca del 6,1\% de esa ganancia privada. En contraste, la ganancia por valorización de suelo que reciben los propietarios de casas debido a cercanía de una estación de Metro es marginal, apenas por encima del 5,5\%. Adicionalmente, se encontraron diferencias dependiendo de la línea de Metro, siendo la Línea 4a la que permite a su largo un aumento en la renta de $22,2 \%$, mientras que las líneas 4 y 5 son las que menos generaron ese aumento, con un $16 \%$ y un $11,1 \%$, respectivamente. Estos resultados demuestran, por primera vez en Chile y con un alto nivel de detalle, el aporte indirecto que realiza el Estado a las ganancias de las empresas inmobiliarias en Santiago.

Las políticas de transporte urbano del país no se definen en términos de rentabilizar ciertas zonas, pero la evidencia es concluyente de que sí generan este efecto. No tanto las propiedades de suelo (casas) en general se rentabilizan, sino que, como queda claro, la ganancia inmobiliaria por explotación de ese suelo se rentabiliza en considerablemente mayor medida cuando se está cerca de una estación de Metro, y al menos un 6,1\% de esa ganancia deriva de cada punto adicional de Coeficiente de Constructibilidad, es decir, la decisión de las autoridades municipales de modificar el Plan Regulador.

Se debe abandonar la idea simplista del "valor de suelo" como un concepto abstracto que beneficia a un propietario de suelo abstracto en la ciudad. Se debe 
responder, en cambio, a la pregunta de a quién beneficia la renta de suelo. La separación entre Renta 1 y Renta 2 es un instrumento teórico que permite resolver esa cuestión (Smith, 1979).

Un corolario evidente es la necesidad de establecer un impuesto a la valorización de la ganancia inmobiliaria (Renta 2) por efecto de inversiones del Estado en la ciudad. Una medida simple puede ser considerar un royalty "promedio" a la valorización de la renta de suelo para el AMGs, que debería ser de al menos un 30\% de las ganancias generadas por cada metro cuadrado de vivienda vendida, correspondiente a la parte generada por accionar estatal en esas ganancias actualmente privatizadas. El 70\% restante de la ganancia puede ser de disfrute privado, dado el legítimo derecho a esa retribución que tienen las inmobiliarias como ganancia derivada del proceso de producción de viviendas, siendo aún un porcentaje considerablemente alto. Una discusión complementaria, pero que exigiría análisis adicional, es el monto del royalty, que también debería ser cobrado en otras ciudades importantes del país, sujetas a otras condiciones (inexistencia de Metro, por ejemplo).

Como se ve en los resultados, sería un error cobrarle el royalty de valorización al propietario (Renta 1) y no al desarrollador (Renta 2 ), por ejemplo, vía un aumento en las Contribuciones de Bienes Raíces al primero, o un impuesto al momento de vender sus casas. Como queda demostrado en este análisis, el propietario se beneficia apenas un 5,5\% por cercanía a Metro, en contraste con el segundo, que actualmente recibe una mucha mayor valorización por la misma causa (25,6\%). Un impuesto a propietarios sería regresivo, ya que gravaría a hogares que podrían tener condiciones socioeconómicas bajas, como ocurre en las principales ciudades chilenas; y de existir exenciones de esta tributación a estos hogares, ello dejaría demasiadas transacciones de compraventa de suelo sin ser gravadas. Distinta situación ocurre para propietarios especuladores que se benefician de la incorporación de sus predios al interior del límite urbano, para quienes sí debe aplicarse un instrumento de carga impositiva distinta.

Gravar la Renta 2 de las empresas inmobiliarias es progresivo, en consideración de que, por una parte, afecta a quienes han estado capturando valor generado por las inversiones del Estado, y lo seguirán haciendo; y por la otra, considerando las múltiples posibilidades que le genera al Estado esta recuperación de valorización de suelo para el financiamiento de políticas más inclusivas de viviendas de interés social, localizadas en suelo central, o para financiar el sistema de transporte público.

Resultaría esperable un efecto de este royalty que en cierta medida encarezca y por la otra reduzca la oferta privada, ya que algunas inmobiliarias podrían decidir no operar bajo estas nuevas condiciones de rentabilidades más normales. De esta forma, ello sería también una buena oportunidad para promover el acceso al mercado de nuevos oferentes, que no estén sujetos a las condiciones actuales en la fijación de precios altos según el modelo de líder-seguidor, y que satisfagan la alta demanda social por residencia en las comunas interiores metropolitanas. 
Inmobiliarias estatales o municipales que cumplan con el fin social de licitar (a constructoras privadas, que son las que generan el empleo) la construcción de vivienda de interés público orientada a la demanda de hogares vulnerables, podría ser una buena alternativa.

\section{Agradecimientos}

Agradecimientos al Centro de Estudios del Conflicto y la Cohesión Social (COEs) y Proyecto Fondecyt \#1151287 por el financiamiento para este proyecto. Agradecimientos al equipo del Centro de Inteligencia Territorial de la Universidad Adolfo Ibáñez, y especialmente a Pía Palacios, por los datos y el análisis facilitados. Agradecimientos a Pablo Trivelli, Luis Valenzuela, Matías Garretón, Elvin Wyly, Juan Pablo Cid, Daniel Meza e Ignacia Saona por el interesante y a veces sustancial feedback recibido. Especiales agradecimientos a Hernán Orozco por el trabajo de cartografía y revisión final del manuscrito, y al ojo crítico de los pares evaluadores, quienes ayudaron sustancialmente a mejorar este manuscrito en su versión final.

\section{Referencias bibliográficas}

Agostini, C. \& Palmucci, G. (2008). Capitalización heterogénea de un bien semipúblico: El metro de Santiago. Cuadernos de Economía, 45(131), 105-128. http://dx.doi. org/10.4067/S0717-68212008000100004

Arriagada, C., Moreno J. \& Cartier, E. (2007). Evaluación de impacto del Subsidio de Renovación Urbana: Estudio del Área Metropolitana del Gran Santiago 1991-2006. Santiago, Chile: Ministerio de Vivienda y Urbanismo. http://www.minvu.cl/ opensite_20070411164455.aspx

Blanco, A., Fretes, V \& Muñoz, A. (eds). (2016). Expandiendo el uso de la valorización del suelo: La captura de plusvalias en América Latina y el Caribe. Washington, D.C.: Banco Interamericano de Desarrollo. https://publications.iadb.org/handle/11319/7799

Bocarejo, J. P., Portilla, I. \& Pérez, M. A. (2013). Impact of Transmilenio on density, land use, and land value in Bogotá. Research in Transportation Economics, 40(1), 78-86. http:// dx.doi.org/10.1016/j.retrec.2012.06.030

Cámara Chilena de la Construcción (сCHC) (2011a). Informe Mach (Macroeconomía y Construcción), 32. Santiago: CCHC. http://www.cchc.cl/uploads/archivos/archivos/ MACh-32.pdf

Cámara Chilena de la Construcción (сCHC). (2011b). Informe Mach (Macroeconomía y Construcción), 34. Santiago: cCHC. http://www.cchc.cl/uploads/archivos/archivos/ MACh-34.pdf

Cox, T. \& Hurtubia, R. (2016). Vectores de expansión urbana y su interacción con los patrones socioeconómicos existentes en la ciudad de Santiago. EURE, 42(127), 185-207. http://dx.doi.org/10.4067/S0250-71612016000300008 
El Mercurio (27 de septiembre de 2014). M² de departamentos en Núñoa y Santiago alcanzan precios de Vitacura y Las Condes. http://impresa.elmercurio.com/Pages/NewsDetail. aspx? $\mathrm{dt}=2014-09-27 \& \mathrm{dtB}=27-09-2014+0 \% 3 \mathrm{~A} 00 \% 3 \mathrm{~A} 00 \&$ PaginaId $=8 \&$ bodyid $=2$

El Mercurio (20 de noviembre de 2017). Nunnoa y Providencia lideran alzas en precios de departamentos durante estadécada.: http://impresa.elmercurio.com/Pages/NewsDetail. aspx?dt=2017-11-20\&dtB=20-11-2017\%200:00:00\&PaginaId=16\&bodyid=2

EMOL (5 febrero de 2016). Precio promedio de viviendas nuevas en el Gran Santiago subió $72 \%$ en la última década. http://www.emol.com/noticias/Economia/2016/02/05/786936/ Precio-promedio-de-viviendas-nuevas-en-el-Gran-Santiago-subio-72-en-la-ultimadecada.html

Evans, A. W. (2004). Economics and land use planning (real estate issues). Londres: Blackwell.

Instituto Nacional de Estadísticas (INE), Chile (2002). Censo Nacional de Población y Vivienda 2002. Base de datos online. http://datos.gob.cl/dataset/4117

Instituto Nacional de Estadísticas (INE), Chile (2012). Resultados preliminares Censo Nacional de Población y Vivienda 2012. https://www.cepal.org/celade/noticias/paginas/2/43712/ Sesion2-Chile.pdf

Lees, L., Slater, T. \& Wyly, E. (2008). Gentrification. Nueva York: Routledge.

Lees, L., Shin, H. \& López-Morales, E. (2016). Planetary gentrification. Cambridge, Ma: Polity Press.

Lefort, F. \& Vargas, M. (2011). Tacit collusion in the Santiago housing market. IDB Serie Documentos de trabajo No. IDB-wp-260. Washington, D.C.: Inter-American Development Bank. https://publications.iadb.org/handle/11319/3396

López-Morales, E. (2011). Gentrification by ground rent dispossession: The shadows cast by large scale urban renewal in Santiago de Chile. International Journal of Urban and Regional Research, 35(2), 330-357. http://dx.doi.org/10.1111/j.1468-2427.2010.00961.x

López-Morales, E. (2015). Assessing exclusionary displacement through rent gap analysis in the urban redevelopment of inner Santiago, Chile. Housing Studies, 31, 540-559. http:// dx.doi.org/10.1080/02673037.2015.1100281

López-Morales, E., Gasic, I. \& Meza, D. (2012). Urbanismo pro-empresarial en Chile: políticas y planificación de la producción residencial en altura en el pericentro del Gran Santiago. Revista INVI, 28(76), 75-114. http://dx.doi.org/10.4067/S0718-83582012000300003

López-Morales, E. \& Herrera, N. (19 julio de 2018). Arriendos por las nubes: efecto de creciente concentración de la propiedad, CIPER. Disponible en: https://ciperchile. cl/2018/07/25/arriendos-por-las-nubes-efecto-de-la-creciente-concentracion-de-lapropiedad/

López-Morales, E., Meza, D. \& Gasic, I. (2014). Neoliberalismo, regulación ad-hoc de suelo y gentrificación: el historial de la renovación urbana del sector Santa Isabel, Santiago. Revista de geografia Norte Grande, (58), 161-177. http://dx.doi.org/10.4067/S071834022014000200009

Marshall, A. (1961). Principles of Economics. Londres: Macmillan.

Marx, K. (1995). Capital. A critique of Political Economy. Volume Three: The process of capitalist production as a whole. En Marxists Internet Archive (ed.). https://www.marxists.org/ archive/marx/works/1894-c3/ 
Méndez, M., Otero, G., López-Morales, E., Link, F. \& Castillo, V. (2016). Ciudad, conflicto y cohesión social: sobre la desigualdad socio-espacial en el Chile actual. Santiago, Chile: Centro de Estudios de Conflicto y Cohesión Social (coes). https://www.coes.cl/wpcontent/uploads/2017/08/N10-ELSOC-MOD3-TERRITORIO.pdf

Mendieta, J. C, \& Perdomo, J. A. (2007). Especificación y estimación de un modelo de precios hedónico espacial para evaluar el impacto de Transmilenio sobre el valor de la propiedad en Bogotá. Documentos Cede No. 2007-22. Bogotá: Centro de Estudios sobre Desarrollo Económico (CEDE). https://teknidataconsultores.com/publicaciones/wp-perdomoTransmileniodCEDE-octubre2007.pdf

Ministerio de Vivienda y Urbanismo (Minvu), Chile. (2017). Observatorio habitacional. Santiago, Chile: Minvu. http://www.observatoriohabitacional.cl/opensite_20080220163307. aspx

Mirrlees, J., Adam, S., Besley, T., Blundell, R., Bond, S., Chote, R., Gammie, M., Johnson, P., Myles, G. \& Poterba, J. (eds.) (2011). Tax by design. The Mirrlees Review. Oxford: Oxford University Press. https://www.ifs.org.uk/publications/5353

Muñoz-Raskin, R. (2010). Walking accessibility to bus rapid transit: Does it affect property values? The case of Bogota, Colombia. Transport Policy, 17(2), 72-84. https://doi. org/10.1016/j.tranpol.2009.11.002

Ricardo, D. (1817). On The Principles of Political Economy and Taxation. Londres: John Murray.

Sabatini, F. (2000). Reforma de los mercados de suelo en Santiago, Chile: efectos sobre los precios de la tierra y la segregación residencial. EURE, 23(77), 49-80. http://dx.doi. org/10.4067/S0250-71612000007700003

Sabatini, F., Rasse, A., Cáceres, G., Robles, M. S. \& Trebilcock, M. P. (2017). Promotores inmobiliarios, gentrificación y segregación residencial en Santiago de Chile. Revista Mexicana de Sociología, 79(2), 229-260. http://www.scielo.org.mx/scielo. php?pid=S0188-25032017000200229\&script=sci_arttext

Sandroni, P. (2011). Recent experience with land value capture in São Paulo, Brazil. Land Lines, 23(3), 14-19. https://www.lincolninst.edu/publications/articles/recent-experienceland-value-capture-sao-paulo-brazil

Smith, N. (1979). Toward a theory of gentrification A back to the city movement by capital, not people. Journal of the American Planning Association, 45(4), 538-548. https://doi. org/10.1080/01944367908977002

Smolka, M. (2013). Implementing value capture in Latin America: policies and tools for urban development. Policy Focus Report Series. Cambridge, MA: Lincoln Institute of Land Policy. https://www.lincolninst.edu/sites/default/files/pubfiles/implementing-valuecapture-in-latin-america-full_1.pdf

Trivelli Consultora (varios años). Boletín de mercado de suelo del Gran Santiago. Santiago.

Trivelli, P. (2011). La propuesta de modificación del Plan Regulador Metropolitano de Santiago PRMS 100 requiere una justificación más sólida. EURE, 37(111), 179-184. http:// dx.doi.org/10.4067/S0250-71612011000200009

Vicuña del Río, M. (2013). El marco regulatorio en el contexto de la gestión empresarialista y la mercantilización del desarrollo urbano del Gran Santiago, Chile. Revista INVI, 28(78), 181-219. http://dx.doi.org/10.4067/S0718-83582013000200006

Wainer, P., Gasic, I. \& Bauzá, M. (2016). Grandes promotores inmobiliarios. Oferta y mercado objetivo. Santiago Metropolitano. Santiago: Inciti. 